\title{
Spatial variability in habitat temperature may drive patterns of selection between an invasive and native mussel species
}

\author{
Kimberly R. Schneider ${ }^{1,2, *}$, Brian Helmuth ${ }^{1}$ \\ ${ }^{1}$ Department of Biological Sciences, University of South Carolina, 700 Sumter Street, Columbia, South Carolina 29208, USA \\ ${ }^{2}$ Present address: Department of Biology, University of Central Florida, 4000 Central Florida Boulevard, Orlando, \\ Florida 32816-2368, USA
}

\begin{abstract}
To understand the mechanisms of invasions it is necessary to explore how thermal environments affect the distribution of both native and invasive species. We examined patterns of species distribution at several scales to determine how thermal selection affects the distribution of native (Mytilus trossulus) and invading ( $M$. galloprovincialis) mussels inhabiting marine rocky intertidal and subtidal habitats. Previous work on these species has focused on the role of water temperature in setting distribution patterns, neglecting the role of aerial exposure at low tide. We therefore examined patterns of abundance in shaded and sun-exposed intertidal habitats and in intertidal versus subtidal habitats at sites within the San Francisco Bay over 3 yr. At half (2/4) of the sites the abundance of the native mussel was significantly higher in shaded intertidal habitats compared to warmer, sun-exposed intertidal habitats, where the invasive mussels were more abundant. Additionally, when comparisons were made between paired subtidal and intertidal sites, native mussel abundance was higher in subtidal habitats. In general, however, there was an unexplained and steady decrease in M. trossulus abundance at all sites. Field transplant experiments showed that the native mussel had lower survivorship than the invading species in all habitats examined (subtidal, shaded, and sunexposed intertidal). Overall survivorship was lowest for both species in the sun-exposed intertidal treatments. This study shows that physiological stress associated with aerial exposure is likely to contribute to the local and geographic distribution of these mussel species. Moreover, our results suggest that processes that operate over larger geographic scales may be experimentally detectable over much smaller scales.
\end{abstract}

KEY WORDS: Climate change $\cdot$ Body temperature $\cdot$ Exposure $\cdot$ Emersion $\cdot$ Hybrid zone $\cdot$ Mytilus trossulus $\cdot$ Mytilus galloprovincialis $\cdot$ Rocky intertidal

\section{INTRODUCTION}

Climate change may play an important role in driving species invasion (Dukes \& Mooney 1999, Stachowicz et al. 2002). Explaining the mechanisms of invasions, especially under future climate scenarios, is imperative due to the large economic and environmental costs of invaders (Pimentel et al. 2000). However, the spatial and temporal scales over which environmental variables such as climate and habitat determine patterns of invasions are not always clear (Helmuth et al. 2006). While climatic gradients operate over large spatial scales, the effects of these largescale systems are often modified by local- and regional-scale processes, so that variability over small scales can exceed that observed over larger geographic scales (Helmuth \& Hofmann 2001). For example, shading by substratum can lead to large temperature differences that are much greater than average differences observed over large geographic gradients (Helmuth 2002). Our understanding of how environmental conditions relate to species distribution patterns, and the scales over which these processes vary, is in some cases limited. Here, we investigate environ- 
mental temperature patterns over several spatial scales and compare these against distributions of a native and invading sibling species. Specifically, we explore how climate, and climate change, may affect invasion success by examining the patterns of body temperature within an invaded community.

Temperature-driven patterns are perhaps most obvious over large spatial scales, such as across altitudinal and latitudinal gradients (e.g. Roy et al. 1998), but similar patterns can also occur at much smaller scales (e.g. Connell 1972). The natural complexity of thermal environments thus presents an excellent and underutilized opportunity to explore the role of the physical environment in driving patterns of species invasion. For example, if 2 species overlap at the edges of their geographic distributions, and one is hypothesized to be warm adapted and the other cold adapted, these species should also be restricted to microhabitats suited to their thermal preference where they co-occur. In other words, from the viewpoint of the organism, whenever they are limited by physiological stress (i.e. are restricted to their fundamental niche space), then this limitation should occur regardless of the spatial scale of the environment examined. These patterns may be of particular interest in invaded communities where the invasive species may be exploiting different thermal niches than the native species.

Marine rocky intertidal ecosystems provide a unique opportunity to study the effects of body temperature, and subsequently climate change, on invasive and native species distribution at a variety of scales. A large degree of thermal variability occurs in this habitat due to diurnal tidal fluctuations and substrate heterogeneity (Helmuth \& Hofmann 2001). To date, most studies of the effects of temperature on the distribution of intertidal species have focused on geographic patterns in sea-surface temperature (e.g. Suchanek et al. 1997). However, during aerial exposure at low tide, organisms must cope with thermal extremes far beyond those suggested by water temperature alone (Helmuth 2002). Patterns of aerial body temperatures of intertidal organisms can differ significantly from patterns in both water and air temperature (Helmuth et al. 2002, 2006). Exposure during low tide can have profound physiological and ecological effects on the life history of intertidal organisms (e.g. Przeslawski 2005, Hofmann \& Somero 1996a). Additionally, differences in body temperature due to microhabitat variation (e.g. substrate angle or tidal height) during low tide can be greater than the differences observed over a $2000 \mathrm{~km}$ gradient (Helmuth \& Hofmann 2001, Helmuth 2002). Thus, natural selection due to thermal stress that occurs over large spatial scales (e.g. 1000s of kilometers) can also be captured on smaller scales (e.g. centimeters) in the rocky intertidal.
Detecting patterns of thermal selection is difficult, especially in complex ecosystems where numerous abiotic and biotic forces are important to species survival. However, when thermally differentiated habitats (e.g. north- versus south-facing substrate) show similar genotype-by-habitat associations (e.g. 1 genotype is consistently more abundant in the cooler habitat), such patterns can potentially be viewed as a signature of thermal selection between the genotypes (Rand et al. 2002). These repeated patterns help support the conclusion that selection and not genetic drift is at work in maintaining observed variation in a natural population. For example, Schmidt \& Rand (1999) showed that intertidal barnacles exhibit repeatable zonation in genotype frequencies at the Mpi locus between habitats with varying levels of thermal stress (Schmidt \& Rand 1999, Rand et al. 2002). In contrast, neutral markers showed no zonation differences, signifying that selection was acting at or near the Mpi locus (Schmidt \& Rand 1999). Here, we investigate spatial patterns of body temperature in 2 congeneric species of mussel, 1 native (Mytilus trossulus) and 1 invasive ( $M$. galloprovincialis), to determine how aerial body temperature (and in particular heat stress) may differentially affect the distribution of these 2 species.

Mussels within the Mytilus edulis complex (M. edulis, M. galloprovincialis, and M. trossulus) are ecologically important members of rocky intertidal communities (Seed 1992). M. edulis is found in cold-temperate communities in the Atlantic, $M$. trossulus is a northern species in the Atlantic and Pacific, and M. galloprovincialis predominates in warm-temperate intertidal areas and is native to the Mediterranean and western Europe (Seed 1992). M. galloprovincialis is considered one of the world's most successful invasive species (Lowe et al. 2000). This species has invaded the USA, South Africa, Japan, Hong Kong, as well as possibly the east China coast into Korea and the Soviet Union (see Seed 1992 and references therein). Selection also favors survival of $M$. galloprovincialis over $M$. edulis in a hybrid zone in southwest England, where it naturally occurs (Hilbish et al. 2002, Gilg \& Hilbish 2003, Schneider et al. 2005).

Along the west coast of the United States, Mytilus galloprovincialis was introduced in the early 1900s into southern California, where $M$. trossulus was once endemic (Geller 1999). Today, in southern California, mussels in the $M$. edulis complex are almost solely M. galloprovincialis, while mussels in Oregon are predominately M. trossulus (Rawson et al. 1999). Currently the 2 species are sympatric in central and northern California, where they form a hybrid zone (Sarver \& Foltz 1993, Suchanek et al. 1997, Braby \& Somero 2006a).

Mussel survival has been correlated to numerous factors, such as salinity, silt, and water temperature 
(e.g. Sarver \& Foltz 1993, Braby \& Somero 2006a). To date, though, most studies have focused on the role of water temperature in structuring global Mytilus spp. distribution patterns. Observational work has geographically correlated $M$. trossulus and M. galloprovincialis' thermal preference: $M$. trossulus prefers habitats with cooler water and $M$. galloprovincialis prefers warmer water (Sarver \& Foltz 1993, Suchanek et al. 1997). Additionally, the 2 species are distinct with respect to their physiological response to heat stress; M. galloprovincialis is better adapted to warm water than M. trossulus (Hofmann \& Somero 1996b, Braby \& Somero 2006b). However, physiological studies also suggest that tolerance to aerial temperatures is likely to be an important determinant of Mytilus spp. survival in intertidal systems (Hofmann \& Somero 1996a).

Research has suggested that our understanding of how thermal stress affects distribution patterns in the intertidal zone may be incomplete. Complexities in the intertidal thermal environment have been shown along the west coast of the United States, where thermal stress experienced by an organism during low tide does not fit a simple latitudinal cline. Instead, patterns of aerial body temperature appear to follow a thermal mosaic pattern, whereby temperatures wax and wane at a series of 'hot' and 'cold' spots due to the interaction of low tides and climate (Helmuth 2002, Helmuth et al. 2002, 2006). For example, some northern sites experience warmer aerial thermal regimes than southern sites due to the timing of low tide in the summer. Understanding the effect of low tide thermal stress on intertidal species is therefore essential to understanding the current distribution patterns of intertidal organisms and to predicting invasion potential. However, the effect of aerial thermal stress during low tide on the distribution of mussels within the Mytilus edulis complex remains virtually unexplored.

Here, we tested the hypothesis that patterns of thermal selection, specifically warm temperatures, should be evident over a range of scales, including within microhabitats (shaded vs. sun-exposed) and between habitats (intertidal vs. subtidal). We examined the variation in distribution patterns of Mytilus galloprovincialis, which has replaced or hybridized with $M$. trossulus along the west coast of the United States, to understand the role of aerial body temperature in driving the distribution of these species. We reasoned that, if an aspect of aerial thermal stress sets the geographic limits of $M$. galloprovincialis and $M$. trossulus, then the same patterns should be detected on smaller spatial scales. Specifically, we hypothesized that the invasive species, $M$. galloprovincialis, should have a greater ability to survive warm thermal stress and, thus, should be found in greater abundance in thermally stressful environ- ments (sun-exposed intertidal with higher daily maximum and larger daily variation) than in thermally benign (shaded and subtidal) habitats.

\section{MATERIALS AND METHODS}

To examine the role that body temperature plays in Mytilus distribution patterns both observational and experimental data were collected from the central California M. galloprovincialis and M. trossulus hybrid zone. Variations in distributional patterns were tested between multiple intertidal microhabitats and between intertidal and subtidal habitats. Mussels within the hybrid zone were then experimentally transplanted into thermally manipulated habitats in the field to investigate survival differences between the species.

Field sites. We chose replicate intertidal sites in the San Francisco Bay (SFB), California, where mussels in the Mytilus edulis complex are the competitively dominant invertebrates. SFB is an ideal location for this research because it appears to be recruitment limited (Braby 2004) and not all the space that appears to be suitable habitat is occupied (K. R. Schneider unpubl. data). Thus, competition for space is likely less of an issue compared to outer coast intertidal systems, making it easier to manipulate and study abiotic processes such as thermal stress. Four intertidal sites were used in this study (Fig. 1). These sites were: San Rafael intertidal (SFI), in China Camp State Park-38 $00.04^{\prime} \mathrm{N}$, $122^{\circ} 27.69^{\prime} \mathrm{W}$; Alameda intertidal (AI) $-37^{\circ} 46.17^{\prime} \mathrm{N}$, $122^{\circ} 17.47^{\prime} \mathrm{W}$; Candlestick State Park intertidal (CSI) $37^{\circ} 42.63^{\prime} \mathrm{N}, 122^{\circ} 23.08^{\prime} \mathrm{W}$; and San Bruno intertidal $(\mathrm{SBI})-37^{\circ} 38.99^{\prime} \mathrm{N}, 122^{\circ} 22.81^{\prime} \mathrm{W}$. With the exception o CSI, each intertidal site was paired with a local subtidal site to allow examination between habitats within a given site: San Rafael subtidal (SFS), at Loch Lomond Marina $-37^{\circ} 58.38^{\prime} \mathrm{N}, 122^{\circ} 28.98^{\prime} \mathrm{W}$; Alameda subtidal, at Ballena Isle Marina (AS) $-37^{\circ} 46.02^{\prime} \mathrm{N}$, $122^{\circ} 17.28^{\prime} \mathrm{W}$; and San Bruno subtidal, at Brisbane Marina in Brisbane (SBS) $-37^{\circ} 40.37^{\prime} \mathrm{N}, 122^{\circ} 22.87^{\prime} \mathrm{W}$.

Field observations. Collections were made at the 4 intertidal sites in late May/early June in 2003, 2004, and 2005. Mussels were taken from 2 microhabitats, shaded and sun-exposed, and from a wide variety of size classes. The sizes of the intertidal mussels ranged from 7 to $80 \mathrm{~mm}$ in shell length (shell length average \pm standard deviation: 2003, $38.5 \pm 14.0 \mathrm{~mm}$; 2004, $50.3 \pm 13.2 \mathrm{~mm}$; $2005,53.0 \pm 12.2 \mathrm{~mm}$ ). Shaded mussels were collected from cool locations, usually under rocks or overhangs that were estimated to be exposed to solar radiation for $<25 \%$ of the day. Sun-exposed mussels were collected from horizontal surfaces with limited shading that were likely exposed to solar radiation $>60 \%$ of the day. 


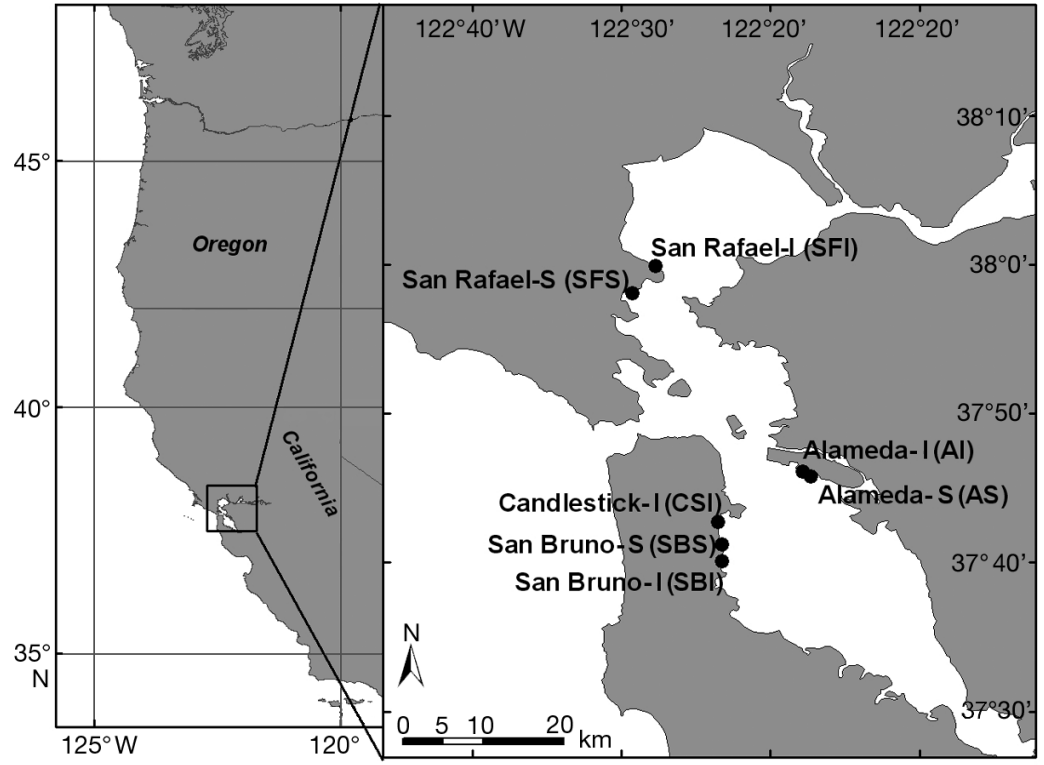

Fig. 1. Mytilus spp. Locations where field collections were made in the San Francisco Bay and the San Pablo Bay in 2003, 2004, and 2005. S: subtidal sites; I: intertidal habitats

Sun-exposed mussels were more difficult to locate then shaded mussels due to the percent of habitat that fit the set criteria. Therefore, whenever a sun-exposed mussel was collected, a shaded mussel was also taken from the same area (when possible).

Approximately 50 mussels were collected from both intertidal microhabitats at all 4 intertidal sites in 2003 and 2004. In 2005, samples were increased to 100 mussels per microhabitat at each site. Temperature loggers (iButton data loggers, Dallas Semiconductor; sample interval of $30 \mathrm{~min}$, accuracy of $\pm 0.5^{\circ} \mathrm{C}$ ) were placed in silicone-filled mussel shells in order to mimic the thermal characteristics of living mussels (Helmuth et al. 2002, Fitzhenry et al. 2004). These biomimetic loggers were deployed in shaded and sun-exposed microhabitats in the mid-intertidal to determine mussel body temperatures in the microhabitats. Sun-exposed loggers were placed in a solitary, horizontal position (i.e. mussel beds do not exist in SFB) that mimicked the growth position of other mussels as closely as possible. Shaded loggers were often placed in cracks/crevices or under rocks and adjacent to the sun-exposed logger. Data were analyzed using the Site Parser program (Gilman et al. 2006), which calculated data as daily averages and daily maximum; these data were summarized as monthly statistics.

Mussels from subtidal locations were collected in late May/early June in 2004 and 2005. These sites were located close to 3 of the intertidal sites (Fig. 1). The shell length of subtidal mussels ranged from 11 to $98 \mathrm{~mm}$ (shell length average \pm standard deviation: 2004, $49.5 \pm 19.4 \mathrm{~mm}$; 2005, $52.4 \pm$ $18.3 \mathrm{~mm})$. Mussels were taken from floating docks at marinas, where it was presumed that water flow and exchange was high (docks close to the opening into the bay). Mussels were collected from the sides of the docks from a variety of patches to ensure random sampling. At least 10 different patches, separated by at least $2 \mathrm{~m}$, were sampled for a total of 100 mussels per collection. For each mussel collected in both intertidal and subtidal collections, a portion of the mantle tissue was preserved in ethanol for genetic identification.

Field transplant experiments. Transplant experiments were set up at San Rafael intertidal, China Camp State Park (SFI; Fig. 1) during summer 2004, spring 2005, and summer 2005. SFI was an ideal location for shading transplants because wave exposure is minimal compared to outer-coast shorelines. All mussels were collected from the SFI intertidal; collections were made randomly from all microhabitats (i.e. shaded, sun-exposed, and the majority coming from intermediate habitats). Collected mussels were kept in flowing seawater from SFB until a small amount of tissue for genetic analyses could be extracted from the mantle tissue during gaping (Rawson et al. 2003). Mussels were then individually tagged with a number and super glue and held in flowing seawater for $48 \mathrm{~h}$ to ensure survival before being transplanted. Mussels were transplanted into hardware cloth cages (1.3 cm gauge). All cages were $625 \mathrm{~cm}^{2}$, with a height of $10 \mathrm{~cm}$. Cages were bolted down onto naturally occurring flat rocky substrate and haphazardly placed in either a shaded or sun-exposed treatment. Shades were made from greenhouse cloth and attached above the cages on stainless steel frames; the frames were set $25 \mathrm{~cm}$ above cages to ensure similar water flow in both shaded and sun-exposed treatments. Five replicate cages of the 2 treatments, each with 30 mussels, were placed in the intertidal at similar tidal heights during the summer of 2004 ( 300 total; 14\% Mytilus trossulus, $49 \%$ hybrid, $27 \%$ M. galloprovincialis). During the spring and summer of 2005, 5 subtidal cages were added to the experimental design and the number of mussels per cage was increased to approximately 40. Subtidal cages were hung off a dock at SFI, which was located $0.5 \mathrm{~km}$ from the intertidal site.

Mussels that died within $48 \mathrm{~h}$ after being transplanted were considered transplant mortality and were removed from the data set. The 2004 transplant experiments began 7 June and were checked in mid-July 
(40 d into the experiment) and mid-September (100 d) for mortality. In 2005, the spring transplants started 7 March were checked in mid-April (40 d) and ended at the end of May (80 d). Summer 2005 transplant experiments began 1 June, were checked in mid-July (40 d) and late August ( $80 \mathrm{~d}$ ), and ran through mid-September (100 d). Biomimetic temperature loggers were placed into a random subset of the cages for each treatment ( 2 to 3 loggers per treatment) to measure the body temperatures mussels experienced during the experiment. The temperature data were analyzed using the Site Parser program (Gilman et al. 2006).

Overall, the transplants proved to be a successful tool in investigating survival; however, some cages were lost or damaged during experimentation. Five replicates were placed in each treatment at the beginning of all experiments. In 2004, 2 shaded and 2 sunexposed cages failed to make it through the entire summer. In spring 2005, 1 cage in each of the 3 treatments was lost. During summer 2005, 1 sun-exposed cage was destroyed and 2 cages in both the subtidal and shaded treatment were lost or damaged by the end of the summer. All data from damaged/lost cages were excluded from analyses. Temperature loggers were recovered from several cages (at least 1 per treatment) in each experimental run, although many loggers malfunctioned, making it impossible to make paired comparisons within a treatment with respect to mussel body temperature. When there were 2 loggers recording data in the replicate treatment cages, the daily high temperatures were averaged.

Genetic analyses. Mussels within the Mytilus edulis complex are morphologically indistinct, but can be distinguished genetically (McDonald et al. 1991). Therefore, all mussels collected from the observational and experimental studies were genetically identified. A diagnostic genetic marker, Glu-5', was assayed using the polymerase chain reaction (PCR). DNA was extracted with phenol chloroform and amplified by PCR according to Rawson et al. (1996). The amplification of the Glu-5' gene produces a species-specific band of about $168 \mathrm{bp}$ for M. trossulus and a $126 \mathrm{bp}$ band for M. galloprovincialis; hybrids have both bands (Inoue et al. 1997). The frequency of these species-specific alleles at the Glu- $5^{\prime}$ marker and several allozyme loci used in previous studies of hybrid mussel populations are strongly correlated (Rawson et al. 1999). Therefore, using 1 genetic locus marker is suitable for determining genotype differences between individuals homozygous for $M$. trossulus $(\mathrm{t} / \mathrm{t})$ or M. galloprovincialis (g/g), and hybrid (heterozygous; $\mathrm{g} / \mathrm{t}$ ) individuals (Rawson et al. 1996, Wilhelm \& Hilbish 1998).

Statistical analyses. For the field observations, we examined the relationship between genotype and habitat (intertidal vs. subtidal and sun-exposed vs. shaded intertidal) using a nominal logistic model, which included collection site and year. All interactions were tested. This test was run (1) between intertidal microhabitats and (2) between all intertidal mussels and subtidal collections. In both models the only significant interaction detected was between habitat and site; therefore, the model was run for each site independently.

Field transplant mortality was examined with an ordinal logistic model (survival was recorded as a binary response) to look for interactions between treatment and mussel length. No interaction was detected between shell length and treatment. A G-test of independence was done to make comparisons between treatments and genotypes at the different times of data collection (Sokal \& Rohlf 1981). Regression analyses were done to examine the correlation between mortality and the average daily maximum body temperature for each species within each experimental run. This was done after $40 \mathrm{~d}$ and after $100 \mathrm{~d}$ (except spring 2005, which was done after $80 \mathrm{~d}$ ).

\section{RESULTS}

\section{Field observations}

Logger data between the shaded and sun-exposed microhabitats revealed large differences in body temperatures between animals living in the 2 aerial environments; differences can be seen in the monthly average daily high, as well as the monthly maximum of each month (Table 1). Mussel body temperature frequently differed by 5 to $10^{\circ} \mathrm{C}$ during the summer between the 2 microhabitats, with a maximum difference of $16.5^{\circ} \mathrm{C}$. Due to lost loggers and equipment failure, data were only available during a portion of the summer of 2003, from all 4 intertidal sites and 2 microhabitats within the site (see Table 1).

Two out of the 4 sites showed significant differences with regard to genotype frequency composition and habitat (SFI, Wald $\chi^{2}=5.8, \mathrm{p}=0.05$; SBI, Wald $\chi^{2}=8.8$, $\mathrm{p}=0.01$; Table 2). The mussel populations at 3 sites (SFI, AI, and SBI) frequently had fewer Mytilus trossulus genotypes in the sun-exposed microhabitat than in the shaded microhabitat, and an increase in M. galloprovincialis and/or hybrid genotypes. Additionally, 3 sites (SFI, CSI, SBI) showed highly significant differences between years $(p<0.0001$; see Table 2$)$. A large decrease in $M$. trossulus genotypes was noted at these sites over the $3 \mathrm{yr}$ of sampling. For example, the frequency of M. trossulus genotypes at CBI was $66.3 \%(\mathrm{n}=104)$ in 2003 , but decreased to $8.5 \%(n=165)$ in 2005 (Table 2). In subtidal versus intertidal comparisons, all 3 sites showed significant differences between these 2 habitats (SFI and SFS, Wald $\chi^{2}=76.3, \mathrm{p}<0.0001$; AI and AS, Wald $\chi^{2}=15.9, \mathrm{p}=$ 
Table 1. Mytilus spp. Body temperature of mussel biomimetic dataloggers placed in the mid-intertidal at sites within the San Francisco Bay in sun-exposed and shaded microhabitats. Data correspond to July 10 to 31 and the entire month of August of 2003, when data were available for all sites and microhabitats. Temperatures correspond to the mean daily maximum each month $( \pm \mathrm{SD})$ and the monthly maximum. SFI: San Rafael intertidal; AI: Alameda intertidal; CSI: Candlestick State Park intertidal; SBI: San Bruno intertidal

\begin{tabular}{|c|c|c|c|c|}
\hline \multirow[t]{2}{*}{ Site } & \multirow[t]{2}{*}{ Month } & \multicolumn{3}{|c|}{$\begin{array}{c}\text { Temperature }\left({ }^{\circ} \mathrm{C}\right) \\
\text { (average daily high } \pm \text { SD } / \text { monthly maximum) }\end{array}$} \\
\hline & & Sun-exposed & Shaded & Difference \\
\hline \multirow[t]{2}{*}{ SFI } & Jul & $28.5 \pm 4.4 / 37.5$ & $26.0 \pm 2.6 / 34.5$ & $2.5 / 3.0$ \\
\hline & Aug & $28.7 \pm 5.4 / 36.0$ & $26.0 \pm 4.0 / 30.5$ & $2.7 / 5.5$ \\
\hline \multirow[t]{2}{*}{ AI } & Jul & $25.4 \pm 6.7 / 40.0$ & $23.0 \pm 3.1 / 32.5$ & $2.4 / 7.5$ \\
\hline & Aug & $26.3 \pm 4.4 / 33.5$ & $23.0 \pm 1.0 / 24.0$ & $3.3 / 9.5$ \\
\hline \multirow[t]{2}{*}{ CSI } & Jul & $24.2 \pm 4.7 / 35.5$ & $22.3 \pm 1.9 / 27.5$ & $1.9 / 8.0$ \\
\hline & Aug & $23.7 \pm 2.6 / 30.0$ & $22.5 \pm 1.0 / 24.5$ & $1.2 / 5.5$ \\
\hline \multirow[t]{2}{*}{ SBI } & Jul & $26.0 \pm 3.7 / 34.0$ & $22.0 \pm 2.2 / 30.0$ & $4.0 / 4.0$ \\
\hline & Aug & $25.5 \pm 3.5 / 33.0$ & $23.1 \pm 1.8 / 27.5$ & $2.4 / 5.5$ \\
\hline
\end{tabular}

Table 2. Mytilus trossulus. Proportion in the sample at all 4 sites in the San Francisco Bay (see Fig. 1) collected from shaded and sun-exposed intertidal microhabitats. Sample sizes are in parentheses. SFI: San Rafael intertidal; AI: Alameda intertidal; CSI: Candlestick State Park intertidal; SBI: San Bruno intertidal

\begin{tabular}{|c|c|c|c|c|c|c|}
\hline \multirow{2}{*}{ Population } & \multicolumn{2}{|c|}{$-2003-$} & \multicolumn{2}{|c|}{2004} & \multicolumn{2}{|c|}{$2005-$} \\
\hline & Shade & Exposed & Shade & Exposed & Shade & Exposed \\
\hline SFI & $0.70(61)$ & $0.60(43)$ & $0.35(48)$ & $0.11(44)$ & $0.08(79)$ & $0.09(86)$ \\
\hline $\mathrm{AI}$ & $0.13(62)$ & $0(37)$ & 0 (39) & $0(40)$ & $0(88)$ & $0(76)$ \\
\hline CSI & $0.45(51)$ & $0.53(45)$ & $0.15(53)$ & $0.18(39)$ & $0.12(96)$ & $0.08(102)$ \\
\hline SBI & $0.41(51)$ & $0.24(54)$ & $0.07(41)$ & $0(32)$ & $0.06(84)$ & $0(90)$ \\
\hline
\end{tabular}

0.0012; SBI and SBS, Wald $\chi^{2}=12.9, \mathrm{p}=0.005$; Fig. 2), and highly significant differences between years (all $\mathrm{p}<$ 0.008; Fig. 2). Fewer hybrid genotypes and more $M$. trossulus genotypes were observed in the subtidal populations.

\section{Field transplant experiments}

\section{Environmental data}

Mean differences between the average daily high mussel body temperature each month for the shaded and sun-exposed treatments were often $>10^{\circ} \mathrm{C}$ during summer experiments (Fig. 3). The subtidal treatments remained the coolest and had the lowest daily temperature range. For example, during the summer of 2005, the average daily temperature ranges were $14.4,8.8$, and $4.0^{\circ} \mathrm{C}$, in the sun-exposed, shaded, and subtidal experi- ments, respectively. In the spring of 2005, the sun-exposed average daily maximum temperature slowly rose in March and April, peaking in May (maximum high of $40^{\circ} \mathrm{C}$ on 25 May), but body temperatures were overall much cooler than those in summer experiments (Fig. 3). Shaded average daily maximum temperature followed a similar trend, but the hottest month was May of the spring 2005 experiment (maximum high of $30^{\circ} \mathrm{C}$ on 14 May; Fig. 3). Summer maximum daily body temperatures in the sun-exposed cages in 2004 and 2005 were between 30 and $40^{\circ} \mathrm{C}$, although data were not available for all months in 2004 due to equipment failure (Fig. 3). In summer 2005, sun-exposed temperatures peaked in July (maximum high of $39^{\circ} \mathrm{C}$ on $15 \mathrm{July}$ ) and declined in August and September (Fig. 3).

\section{Mortality results}

In all experiments, mussel mortality tended to be greatest in the sunexposed intertidal cages. In summer 2004, there were significant differences in mortality between the sun-exposed ( $\mathrm{n}=68)$ and shaded $(\mathrm{n}=71)$ transplants after $40 \mathrm{~d}$ and after $100 \mathrm{~d}\left(100 \mathrm{~d}: \chi^{2}=\right.$ 47.3, p $<0.0001$; Fig. 4). When the genotypes were examined separately, similar patterns were seen within the Mytilus galloprovincialis genotypes $(\mathrm{g} / \mathrm{g}$ :

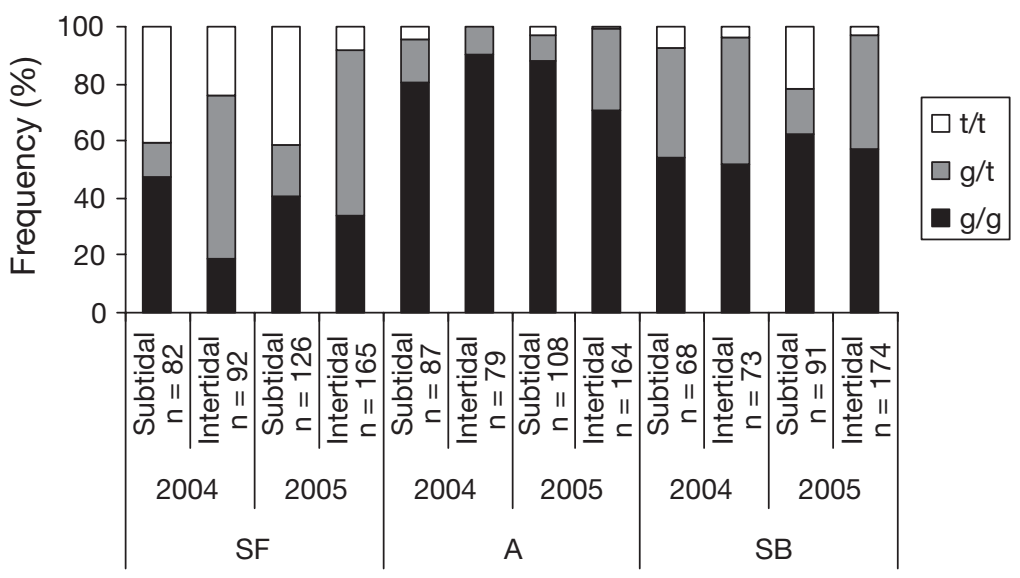

Fig. 2. Mytilus spp. Comparisons in genotype frequency between subtidal and intertidal sites within the San Francisco Bay. SF: San Rafael; A: Alameda; SB: San Bruno; t/t: $M$. trossulus genotype; g/g: M. galloprovincialis genotype; $\mathrm{g} / \mathrm{t}$ : hybrid genotype 


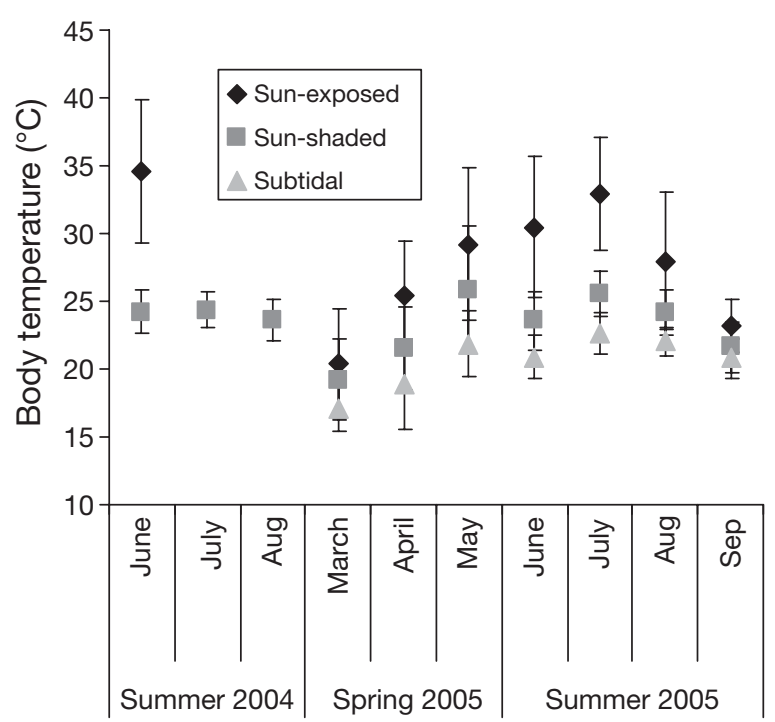

Fig. 3. Mytilus spp. Mean $( \pm \mathrm{SD})$ daily maximum of mussel body temperature, as measured by biomimetic mussels, separated into monthly periods from field transplant experiments. 'Shaded' and 'sun-exposed' refer to intertidal thermal exposure; 'subtidal' treatments remained underwater for the duration of the experiment. Experiments were done at San Rafael intertidal

$\left.\mathrm{n}=50, \chi^{2}=23.0, \mathrm{p}<0.0001\right)$ and hybrid genotypes $(\mathrm{g} / \mathrm{t}$ : $\left.\mathrm{n}=67 ; \chi^{2}=23.9, \mathrm{p}<0.0001\right)$, but not for $M$. trossulus (t/t: $\left.\mathrm{n}=22, \chi^{2}=0.3, \mathrm{p}=0.29\right)$, where mortality was high in both treatments.

The spring 2005 experiments produced slightly different results; there were no differences in mortality between the shaded $(\mathrm{n}=130)$ and the sun-exposed $(\mathrm{n}=$ 127 ) intertidal treatments $\left(\chi^{2}=1.6, p=0.2\right)$, but there were significant differences between the subtidal $(\mathrm{n}=$ 139) and the sun-exposed $\left(\chi^{2}=15.1, p=0.0001\right)$ and the shaded treatments $\left(\chi^{2}=7.0, p=0.008\right.$; Fig. 4$)$, with lower mortality in the subtidal treatments. These differences were consistent between 40 and 80 d mortality checks. Most of the mortality in the sun-exposed treatment occurred after the mid-April (40 d) check, as the mean daily maximum temperature increased (Figs. 3 \& 4). Significant differences were not seen between treatments within the Mytilus galloprovincialis $\left(\mathrm{n}=93, \chi^{2}=5.6, \mathrm{p}=0.06\right)$ and $M$. trossulus genotypes $\left(\mathrm{n}=21, \chi^{2}=1.6, \mathrm{p}=0.45\right)$, but were seen within hybrid genotypes $\left(n=268, \chi^{2}=15.2, p=0.0005\right)$, where sample sizes were higher.

In the summer 2005 experiments, mortality in the sun-exposed treatment $(\mathrm{n}=127)$ was significantly higher than in the shaded treatment $\left(\mathrm{n}=111, \chi^{2}=\right.$ 162.7, $\mathrm{p}<0.0001)$ and subtidal treatments $\left(\mathrm{n}=151, \chi^{2}=\right.$ 141.2, $\mathrm{p}<0.0001)$ at the 40, 80, and $100 \mathrm{~d}$ mortality check. Shaded mussel mortality was significantly greater than subtidal mortality after $40 \mathrm{~d}\left(\chi^{2}=4.5, \mathrm{p}=\right.$

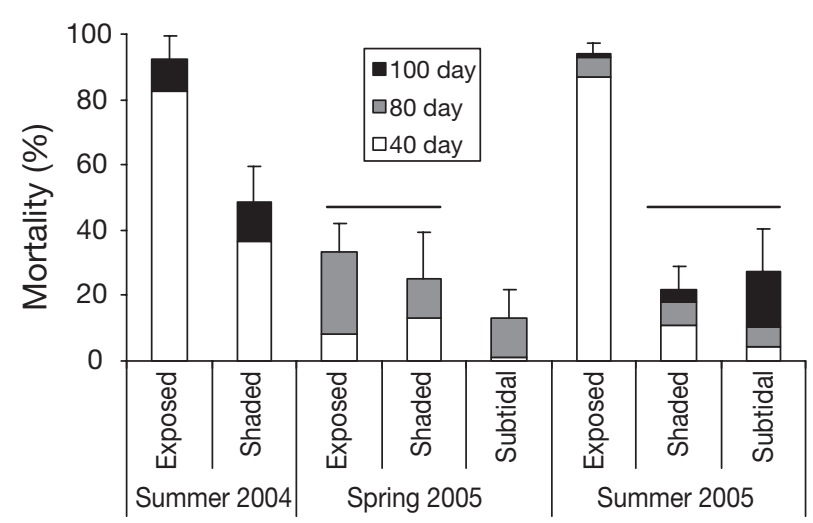

Fig. 4. Mytilus spp. Mean (+SD) percent mortality of all Mytilus species transplanted into 1 of 3 thermal microhabitats. 'Shaded' and 'sun-exposed' refer to intertidal thermal exposure; 'subtidal' treatments remained underwater for the duration of the experiment. Standard deviation bars represent the differences between cages of like treatments. In summer 2004 mortality was checked after 40 and 100 d. In spring 2005, it was checked at 40 and $80 \mathrm{~d}$, and in summer 2005, it was checked at 40, 80, and $100 \mathrm{~d}$. Horizontal line: no significant difference in total mortality between treatments at the last mortality check

$0.34)$, but not after 80 or $100 \mathrm{~d}\left(100 \mathrm{~d}: \chi^{2}=1.2, \mathrm{p}=0.27\right.$; Fig. 4). After $100 \mathrm{~d}$, there was a significant effect of treatment on mortality within each genotype $(\mathrm{g} / \mathrm{g}$ : $\mathrm{n}=$ 117, $\chi^{2}=57.7, \mathrm{p}<0.0001 ; \mathrm{g} / \mathrm{t}: \mathrm{n}=270, \chi^{2}=150.9, \mathrm{p}<$ $\left.0.0001 ; \mathrm{t} / \mathrm{t}: \mathrm{n}=22, \chi^{2}=8.3, \mathrm{p}=0.016\right)$.

After $40 \mathrm{~d}$, the mortality for all 3 genotypes was significantly correlated with average daily maximum body temperature ( $\mathrm{g} / \mathrm{g}: F_{1,6}=24.8, \mathrm{p}=0.003 ; \mathrm{g} / \mathrm{t}: F_{1,6}=$ 46.7, $\mathrm{p}=0.0005$; t/t: $F_{1,6}=13.3, \mathrm{p}=0.01$; Fig. 5a). An ANCOVA suggested that there were no significant differences between genotypes. After 100 d, mortality was not correlated with temperature for Mytilus trossulus genotypes $\left(F_{1,6}=1.6, \mathrm{p}=0.26\right)$; however, temperature and mortality remained correlated in $M$. galloprovincialis $\left(F_{1,6}=16.6, \mathrm{p}=0.007\right)$ and hybrid $\left(F_{1,6}=\right.$ 32.7, $\mathrm{p}=0.001$ ) genotypes (Fig. 5b). M. trossulus had significantly different mortality compared to M. galloprovincialis and hybrid genotypes (ANCOVA, $\mathrm{p}=0.02$; no interactions were detected between species). Overall, in the field experiments, the mortality of $M$. trossulus genotypes was higher $(69 \%)$ than that of M. galloprovincialis genotypes $(40 \%)$ and hybrid genotypes $(37 \%)$ when all data were combined.

\section{DISCUSSION}

Exposure to aerial thermal stress can play an important role in the survival of intertidal species (e.g. Davenport \& Davenport 2005). The importance of aerial body temperature was evident from the shift in species 


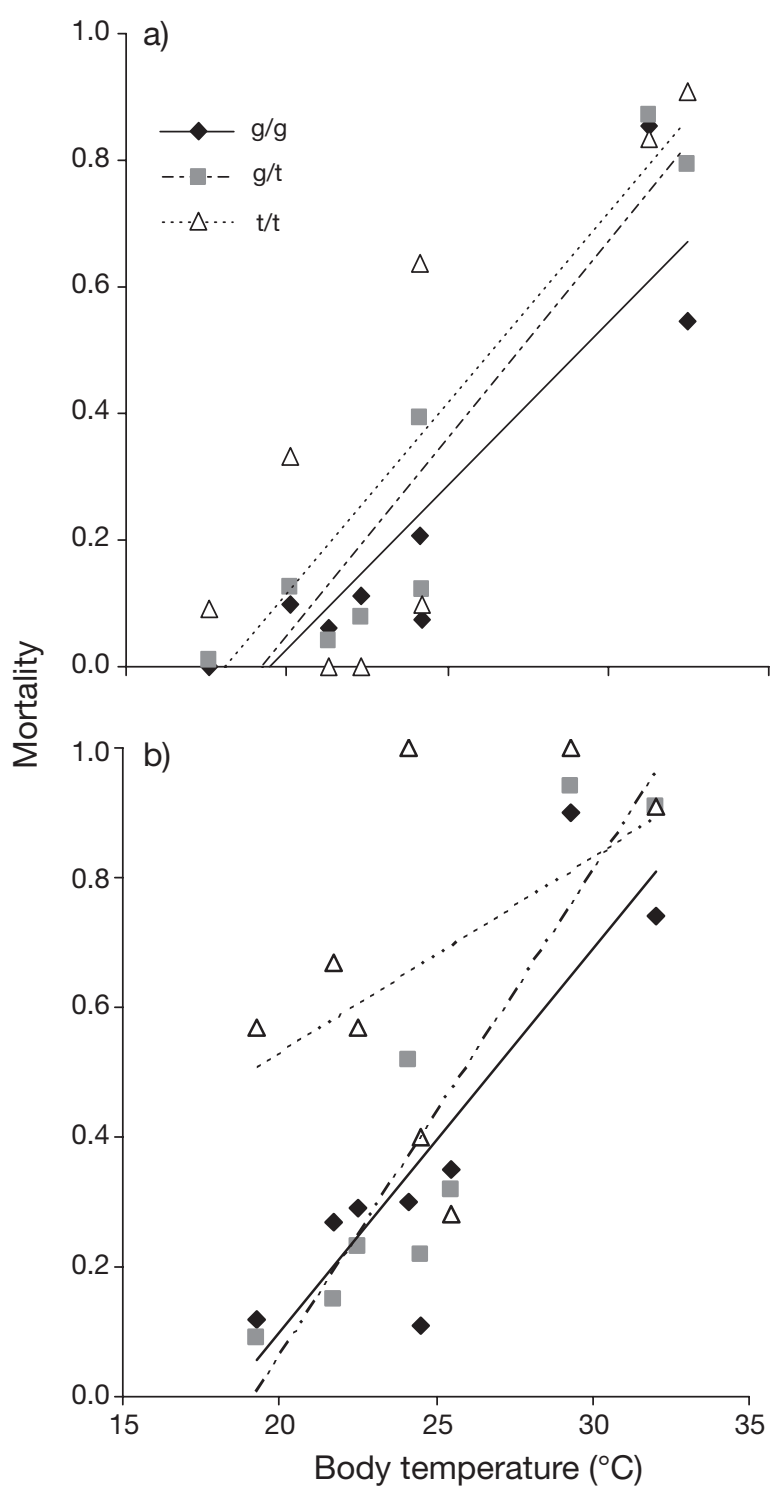

Fig. 5. Mytilus galloprovincialis and M. trossulus. Mortality after (a) $40 \mathrm{~d}$ and (b) $100 \mathrm{~d}$, except spring 2005 treatment, which was after $80 \mathrm{~d}$. Mortality is correlated with the average daily maximum body temperature after 40 or 80/100 d. g/g: M. galloprovincialis genotypes; g/t: hybrid genotypes; t/t: M. trossulus genotypes

abundance patterns between thermally differentiated habitats, as well as the high mortality that occurred in sun-exposed areas in the transplant experiments. Our study elucidates the practical application of examining species abundance patterns between thermally distinct habitats at small scales (e.g. centimeters to kilometers) to gain insights into the role of the physical environment in setting species range limits over a cascade of spatial scales (e.g. centimeters to 1000s of kilometers). Moreover, our study demonstrates the utility of taking such an approach when examining differences in survival between native and invasive species in natural populations.

We explored the survival and abundance patterns of Mytilus galloprovincialis, an invasive mussel, and of $M$. trossulus, a native mussel on the west coast of the United States, in a variety of thermally differentiated habitats. Previous research suggests M. galloprovincialis is better adapted to warm water temperatures compared to M. trossulus (Hofmann \& Somero 1996b, Braby \& Somero 2006b). Our results support the hypothesis that $M$. galloprovincialis is more tolerant of warmer aerial temperatures than $M$. trossulus. M. trossulus was always more abundant in subtidal habitats compared to intertidal habitats. Additionally, 2 out of the 4 intertidal sites showed significantly higher frequencies of $M$. trossulus genotypes in shaded intertidal microhabitats compared to sun-exposed populations. We did not find significant differences in distribution at Alameda, but $M$. trossulus genotypes were very infrequent at this site in 2004 and 2005, and were only found in shaded areas in 2003. One exception to the general trend was the Candlestick intertidal site, where results did not show any significant differences in genotype composition specific to microhabitat. This site is characterized by a high macro-algal abundance (K. R. Schneider pers. obs.), which may buffer temperature extremes (e.g. Stillman \& Somero 1996). Additionally, many factors contribute to the distribution of organisms in the intertidal (e.g. Leonard et al. 1999); therefore, it is not surprising to observe instances where a thermal selection signature does not occur because of the modifying role of other abiotic and biotic factors in an ecosystem (e.g. salinity, food availability, predation).

The observational abundance patterns produced one unexpected, yet interesting result: there was a large decrease in Mytilus trossulus genotypes in our intertidal populations over the $3 \mathrm{yr}$ sampled. The underlying mechanism causing the dramatic decrease in $M$. trossulus genotypes in our population is unclear. Possibly a shift of an abiotic factor (e.g. water or aerial exposure temperature, food availability) occurred in San Francisco Bay that caused mortality in $M$. trossulus, but did not affect hybrid or M. galloprovincialis genotypes. However, this pattern warrants further investigation.

Aerial exposure during low tide can limit the survival of intertidal species at various life stages (e.g. Przeslawski 2005). Therefore, it is not surprising that transplanted Mytilus spp. showed high mortality in the intertidal sun-exposed thermal environment, especially during the summer experiments when temperatures were frequently $>35^{\circ} \mathrm{C}$. The spring experiment produced lower mortality in the sun-exposed treat- 
ments; however, mortality increased during the second half of the spring experiment, when the daily highs were often $>30^{\circ} \mathrm{C}$. Therefore, it appears that aerial heat stress can lead to elevated mortality at mussel body temperatures $>30^{\circ} \mathrm{C}$. This is consistent with an earlier study by Hofmann \& Somero (1996a) who found significantly higher denaturation of cellular proteins in intertidal versus subtidal $M$. trossulus at high temperatures. In their work the body temperature of $M$. trossulus during low tide approached $35^{\circ} \mathrm{C}$. However, in our research, $M$. trossulus had high mortality in all treatments (shaded, sun-exposed, and subtidal) by the end of each experiment (80 or $100 \mathrm{~d}$ ), thus suggesting another stress in addition to aerial exposure, such as sensitivity to transplantation or other abiotic factors consistent between treatments (e.g. water temperature or food availability) that affected $M$. trossulus, but not M. galloprovincialis or hybrids.

The native Mytilus trossulus genotype abundance was lower than expected in the transplant experiments because a large decrease in their abundance was seen between the 2003 sampling, and the 2004 and 2005 samplings. Thus, it was difficult to statistically identify all potential genotypic-related differences in survival between the habitats. $M$. trossulus genotype mortality was high in all habitats, including the shaded and subtidal habitats where mortality was low for M. galloprovincialis and hybrid genotypes (Fig. 5). Thus, exposure to low-tide warm thermal stress is not a full explanation for its decrease in frequency. Results indicate that $M$. galloprovincialis and hybrid genotypes have similar fitness, while the native genotype, $M$. trossulus, has reduced fitness. This is similar to a naturally occurring hybrid zone between $M$. galloprovincialis and $M$. edulis in southwest England, where $M$. edulis genotypes have reduced fitness compared to $M$. galloprovincialis and hybrid genotypes (Wilhelm \& Hilbish 1998). The observational data suggest a difference in $M$. trossulus genotype frequency between habitats. There was a slight decrease in $M$. trossulus genotype survival between less thermally stressful and more stressful conditions in the transplants (shaded versus sun-exposed). However, survival was lower for M. trossulus genotypes compared to hybrid and $M$. galloprovincialis genotypes in all habitats, not just the thermally stressful habitats.

If Mytilus trossulus is more sensitive to low tide heat stress than M. galloprovincialis, can we observe this thermal preference with respect to their geographic distribution along the west coast of the United States? The species' thermal preference with respect to water temperature supports their current distribution patterns: $M$. trossulus is found in cooler water from central California through Alaska and M. galloprovincialis is found from southern California to northern California
(Sarver \& Foltz 1993, Hofmann \& Somero 1996b, Suchanek et al. 1997, Braby \& Somero 2006b). However, temperatures experienced during low tide do not always follow a latitudinal cline (Helmuth et al. 2002, 2006, Gilman et al. 2006). As a result, 'hot spots' occur within the present range of $M$. trossulus (see Helmuth et al. 2002), where summertime low tide coincides with periods of low wave splash and hot climatic conditions. The abundance and/or fitness of $M$. trossulus may be lower in these areas due to thermal stress. If the distribution of $M$. galloprovincialis shifts/expands northward, then this species may perform better than M. trossulus in these 'hot spots'. Under this scenario, a mosaic distribution pattern between these species should emerge, which should already be detectable within the hybrid zone and could be tested on the outer coast between sites with different tidal and/or climatic regimes. However, further research into the role of aerial exposure in the life history of Mytilus spp. is necessary to determine the implications of our data, as well as the potential effect of thermal stress on intertidal distribution patterns in general.

Studies that examine the role of thermal stress in setting species distributions are essential to predicting future distributions of native and non-native species following climate change and/or future species invasions. We established that the invader, Mytilus galloprovincialis, survives better than the native, $M$. trossulus, in all habitats of the transplant experiments, consistent with other findings that successful invaders generally have higher survival rates compared to natives (Byers \& Goldwasser 2001). With an increase in anthropogenic activities that break down barriers to marine organism dispersal (Carlton \& Geller 1993), there is a strong need to understand the mechanisms underlying successful invasions and the interactions between native and exotic species (Grosholz 2002). This work helps explain the relationship between the native and invasive species' distribution patterns through examining physical factors operating over a range of spatial scales. However, as is evident from the complex results, it remains difficult even at small scales to fully explain species' distributions by invoking thermal biology, due to the numerous abiotic and biotic factors (e.g. food, predation, pathogens, interaction with stress) that impact distribution and abundance of all organisms (e.g. Sanford 1999). Therefore, future work should continue to focus on examining survival of both invasive and native species in a variety of thermal habitats. Additionally, considering the affect of temperature on species, it is necessary to investigate the interactions of other environmental parameters (e.g. pollution, food availability, salinity) with the thermal environment (i.e. indirect effects of thermal stress) for various life-history traits. 
Acknowledgements. K. Nylund helped shape ideas in the early stages of this project, and her input was much appreciated. Both K. Nylund and S. Felder helped in the field and with genetic analyses. K. Fedorka, S. Gilman, K. Mills, N. Ragaban, F. Schneider, L. Watson, and C. Welch helped with field experiments, as well as collecting and processing mussels. We appreciate the support of the ranger staff at China Camp State Park, especially P. Robards. SFSU's Romberg Center for Environmental Studies, Tiburon, California, provided work space and logistical support. Earlier forms of this manuscript were improved by comments from S. Gilman, N. Mieszkowska, and R. Raguso. This work was funded by a Slocum-Lunz grant to K.R.S. and by NSF OCE-0323364 and NASA NNG04GE43G to B.H.

\section{LITERATURE CITED}

Braby CE (2004) Physiological ecology of native and invasive blue mussels (genus Mytilus) in Central California. PhD thesis, Stanford University, Palo Alto, CA

Braby CE, Somero GN (2006a) Ecological gradients and relative abundance of native (Mytilus trossulus) and invasive (Mytilus galloprovincialis) blue mussels in the California hybrid zone. Mar Biol 148:1249-1262

Braby CE, Somero GN (2006b) Following the heart: temperature and salinity effects on heart rate in native and invasive species of blue mussels (genus Mytilus). J Exp Biol 209:2554-2566

Byers JE, Goldwasser L (2001) Exposing the mechanism and timing of impact of nonindigenous species on native species. Ecology 82:1330-1343

Carlton JT, Geller JB (1993) Ecological roulette - the global transport of nonindigenous marine organisms. Science 261:78-82

Connell J (1972) Community interactions on marine rocky intertidal shores. Annu Rev Ecol Syst 3:169-192

Davenport J, Davenport JL (2005) Effects of shore height, wave exposure and geographical distance on thermal niche width of intertidal fauna. Mar Ecol Prog Ser 292: 41-50

Dukes JS, Mooney HA (1999) Does global change increase the success of biological invaders? Trends Ecol Evol 14: 135-139

Fitzhenry T, Halpin PM, Helmuth B (2004) Testing the effects of wave exposure, site, and behavior on intertidal mussel body temperatures: applications and limits of temperature logger design. Mar Biol 145:339-349

Geller JB (1999) Decline of a native mussel masked by sibling species invasion. Conserv Biol 13:661-664

Gilg MR, Hilbish TJ (2003) Patterns of larval dispersal and their effect on the maintenance of a blue mussel hybrid zone in southwestern England. Evolution 57:1061-1077

Gilman S, Harley CDG, Strickland D, Vanderstraeten O, O'Donnell M, Helmuth B (2006) Evaluation of 'Effective Shore Level' as a method of characterizing intertidal wave exposure regimes. Limnol Oceanogr Methods 4:448-457

Grosholz E (2002) Ecological and evolutionary consequences of coastal invasions. Trends Ecol Evol 17:22-27

Helmuth B (2002) How do we measure the environment? Linking intertidal thermal physiology and ecology through biophysics. Integr Comp Biol 42:837-845

Helmuth BST, Hofmann GE (2001) Microhabitats, thermal heterogeneity, and patterns of physiological stress in the rocky intertidal zone. Biol Bull (Woods Hole) 201:374-384

Helmuth B, Harley CDG, Halpin PM, O'Donnell M, Hofmann GE, Blanchette CA (2002) Climate change and latitudinal patterns of intertidal thermal stress. Science 298: 1015-1017

Helmuth B, Broitman BR, Blanchette CA, Gilman S and 6 others (2006) Mosaic patterns of thermal stress in the rocky intertidal zone: implications for climate change. Ecol Monogr 76:461-479

Hilbish TJ, Carson EW, Plante JR, Weaver LA, Gilg MR (2002) Distribution of Mytilus edulis, M. galloprovincialis, and their hybrids in open-coast populations of mussels in southwestern England. Mar Biol 140:137-142

Hofmann GE, Somero GN (1996a) Protein ubiquitination and stress protein synthesis in Mytilus trossulus occurs during recovery from tidal emersion. Mol Mar Biol Biotechnol 5: $175-184$

Hofmann GE, Somero GN (1996b) Interspecific variation in thermal denaturation of proteins in the congeneric mussels Mytilus trossulus and M. galloprovincialis: evidence from the heat shock response and protein ubiquitination. Mar Biol 126:65-75

Inoue K, Odo S, Noda T, Nakao S, Takeyama S, Yamaha E, Yamazaki F, Harayama S (1997) A possible hybrid zone in the Mytilus edulis complex in Japan revealed by PCR markers. Mar Biol 128:91-95

Leonard GH, Ewanchuk PJ, Bertness MD (1999) How recruitment, intraspecific interactions, and predation control species borders in a tidal estuary. Oecologia 118: 492-502

Lowe S, Browne M, Boudjelas S, Poorter M (2000) 100 of the world's worst invasive alien species. A selection from the global invasive species database. Invasive Species Specialist Group (ISSG) of the Species Survival Commission (SSC) of the World Conservation Union (IUCN), Hollands Printing, Auckland

McDonald JH, Seed R, Koehn RK (1991) Allozymes and morphometric characters of three species of Mytilus in the northern and southern hemispheres. Mar Biol 111: 323-333

Pimentel D, Lach L, Zuniga R, Morrison D (2000) Environmental and economic costs of nonindigenous species in the United States. Bioscience 50:53-65

Przeslawski R (2005) Combined effects of solar radiation and desiccation on the mortality and development of encapsulated embryos of rocky shore gastropods. Mar Ecol Prog Ser 298:169-177

Rand DN, Spaeth PS, Sackton TB, Schmidt PS (2002) Ecological genetics of Mpi and Gpi polymorphisms in the acorn barnacle and the spatial scale of neutral and non-neutral variation. Integr Comp Biol 42:825-836

Rawson PD, Joyner KL, Meetze K, Hilbish TJ (1996) Evidence for intragenic recombination within a novel genetic marker that distinguishes mussels in the Mytilus edulis species complex. Heredity 77:599-607

Rawson PD, Agrawal V, Hilbish TJ (1999) Hybridization between the blue mussels Mytilus galloprovincialis and M. trossulus along the Pacific coast of North America: evidence for limited introgression. Mar Biol 134:201-211

Rawson PD, Slaughter C, Yund PO (2003) Patterns of gamete incompatibility between the blue mussels Mytilus edulis and M. trossulus. Mar Biol 143:317-325

Roy K, Jablonski D, Valentine JW, Rosenberg G (1998) Marine latitudinal diversity gradients: tests of causal hypotheses. Proc Natl Acad Sci USA 95:3699-3702

Sanford E (1999) Regulation of keystone predation by small changes in ocean temperature. Science 283:2095-2097

Sarver SK, Foltz DW (1993) Genetic population-structure of a species complex of blue mussels (Mytilus spp.). Mar Biol 117:105-112 
Schmidt PS, Rand DM (1999) Intertidal microhabitat and selection at Mpi: interlocus contrasts in the northern acorn barnacle, Semibalanus balanoides. Evolution 53: 135-146

Schneider KR, Wethey DS, Helmuth BST, Hilbish TJ (2005) Implications of movement behavior on mussel dislodgement: exogenous selection in a Mytilus spp. hybrid zone. Mar Biol 146:333-343

Seed R (1992) Systematics evolution and distribution of mussels belonging to the genus Mytilus - an overview. Am Malacol Bull 9:123-137

Sokal RR, Rohlf FJ (1981) Biometry. WH Freeman \& Company, New York

Stachowicz JJ, Terwin JR, Whitlatch RB, Osman RW (2002)

Linking climate change and biological invasions: ocean

Editorial responsibility: Matthias Seaman (Assistant Editorin-Chief), Oldendorf/Luhe, Germany warming facilitates nonindigenous species invasions. Proc Natl Acad Sci USA 99:15497-15500

Stillman JH, Somero GN (1996) Adaptation to temperature stress and aerial exposure in congeneric species of intertidal porcelain crabs (genus Petrolisthes): correlation of physiology, biochemistry and morphology with vertical distribution. J Exp Biol 199:1845-1855

Suchanek TH, Geller JB, Kreiser BR, Mitton JB (1997) Zoogeographic distributions of the sibling species Mytilus galloprovincialis and $M$. trossulus (Bivalvia: Mytilidae) and their hybrids in the North Pacific. Biol Bull (Woods Hole) 193:187-194

Wilhelm R, Hilbish TJ (1998) Assessment of natural selection in a hybrid population of mussels: evaluation of exogenous vs endogenous selection models. Mar Biol 131:505-514

Submitted: June 30, 2006; Accepted: November 10, 2006 Proofs received from author(s): May 17, 2007 